"This accepted author manuscript is copyrighted and published by Elsevier. It is posted here by agreement between Elsevier and MTA. The definitive version of the text was subsequently published in [Nuclear Instruments and Methods in Physics Research A 832 (2016) 254-258; DOI 10.1016/j.nima.2016.06.132]. Available under license CC-BYNC-ND." 


\title{
Coating and functionalization of high density ion track structures by atomic layer
}

\section{deposition}

\author{
Laura Mättö $^{1}$, Imre M. Szilagyi ${ }^{2,3,4^{*}}$, Mikko Laitinen ${ }^{1}$, Mikko Ritala ${ }^{4}$, Markku Leskelä ${ }^{4}$, Timo \\ Sajavaara $^{1}$
}

\footnotetext{
${ }^{1}$ Department of Physics, University of Jyväskylä, P.O. Box 35 (YFL), FI-40014, Finland

${ }^{2}$ Department of Inorganic and Analytical Chemistry, Budapest University of Technology and
} Economics, Budapest, Szent Gellért tér 4, H-1111, Hungary

${ }^{3}$ MTA-BME Technical Analytical Research Group, Budapest, Szent Gellért tér 4, H-1111, Hungary

${ }^{4}$ Department of Chemistry, University of Helsinki, Helsinki, P.O. Box 55, FI-00014, Finland

Email: imre.szilagyi@mail.bme.hu

\begin{abstract}
In this study flexible $\mathrm{TiO}_{2}$ coated porous Kapton membranes are presented having electron multiplication properties. $800 \mathrm{~nm}$ crossing pores were fabricated into $50 \mu \mathrm{m}$ thick Kapton membranes using ion track technology and chemical etching. Consecutively, $50 \mathrm{~nm} \mathrm{TiO}_{2}$ films were deposited into the pores of the Kapton membranes by atomic layer deposition using $\mathrm{Ti}\left({ }^{\mathrm{i}} \mathrm{OPr}\right)_{4}$ and water as precursors at $250{ }^{\circ} \mathrm{C}$. The $\mathrm{TiO}_{2}$ films and coated membranes were studied by scanning electron microscopy (SEM), X-ray diffraction (XRD) and X-ray reflectometry (XRR). Au metal electrode fabrication onto both sides of the coated foils was achieved by electron beam evaporation. The electron multipliers were obtained by joining
\end{abstract}


two coated membranes separated by a conductive spacer. The results show that electron multiplication can be achieved using ALD-coated flexible ion track polymer foils.

Keywords: nanostructures, oxides, polymers, thin films, coatings, electrical properties

\section{Introduction}

Porous materials with precisely controlled properties, such as pore size and diameter, have several applications in, for instance, filtration [1], gas sensing [2,3], catalysis [4], photocatalysis [5,6], solar cells [7], adsorption [8,9], and biomedical research [10]. Microchannel plates (MCPs) are special member of these materials, in which a porous membrane is composed of parallelly aligned or crossing tubes. An MCP is an array of miniature electron multipliers that are each acting as a continuous dynode chain. They can be used e.g. in night vision applications, photomultipliers, particle and time-of-flight detectors [11].

One method to fabricate porous films is to shoot single heavy energetic ions through a material to be manipulated. In ion track method [12] these ions with typical energies of several hundred MeVs are generated by means of an accelerator. When these ions hit the target material, they lose their energy by various interactions with the material, and cause excitation and ionization of target electrons (electronic energy loss), projectile excitation and ionization, electron capture, elastic collisions with target atoms (nuclear energy loss) and electromagnetic radiation. For high energy heavy ions the most significant process is the electronic energy loss. The incident ions are chosen in such a way that the energy transfer to the material is large. The electronic energy loss can be well described by the Bethe-Bloch formula and the SRIM software [13]. The incident ion induces ionization and electric 
excitation, which in polymers predominantly breaks chemical bonds and a damaged ion track forms.

After the ion irradiation the pore is created via chemical etching process. The shape of the etched pore depends on the etch velocity of the bulk material $V_{b}$ (etch rate of undamaged material) and the etch velocity of track line $V_{t}$ (etch rate along the track). Both depend on the etching conditions and $V_{t}$ is also influenced by the energy loss of the irradiated ions. $V_{t}$ increases with increasing energy loss due to higher damage along the ion track [14]. Size of the pore varies with the etching time, as well as the $\mathrm{pH}$ and temperature of the solution. Atomic layer deposition (ALD) is a gas phase thin film deposition method based on surface controlled self-limiting reactions of volatile precursors, which are introduced into the reaction chamber alternately. ALD can be used to coat not only flat substrates, but also complex surfaces and highly porous materials with uniform films having thickness even down to single nanometers $[15,16]$. These films can be, for instance, insulating oxides or conducting metals, ternary compounds or polymers [17,18]. These features make ALD a convenient choice for modifying the surface properties of various nanostructures [19-21] or even sensitive substrates such as biomaterials [22].

In previous work by others, ion track structures and ALD have been combined to make nanotubes after dissolving the soluble nano templates [23]. On the other hand, ALD has been used to coat with thin films MCP structures made of glass [24], lead glass [25], borosilicate glass [26,27], porous silicon [28] and anodized $\mathrm{Al}_{2} \mathrm{O}_{3}$ [29]. These ALD-MCP structures showed mostly similar or even better properties than conventional MCPs based on lead glass, and had increased gain and improved stability as a function of extracted charge in several cases. However, all these substrates were rigid materials, and for MCP applications flexible MCP structures might have obvious advantages in several fields (e.g. night vision). Also MCP devices from plastic materials have been previously reported [30,31]. These devices 
were made out of porous polymethyl methacrylate (PMMA) having pore size and thickness of $50 \mu \mathrm{m}$ and $5 \mathrm{~mm}$, respectively. The polymer channels had separate unspecified conductive and emissive low-temperature ALD coatings. The electron yield was amplified with additional conventional MCP stack after the polymer MCP. In ALD coated MCP structures various secondary electron emissive layers were deposited, e.g. $\mathrm{MgO}, \mathrm{MgO} / \mathrm{TiO}_{2}, \mathrm{TiO}_{2}$, etc [32]. Though $\mathrm{TiO}_{2}$ is a less common material for secondary electron emission, its easy ALD deposition makes it a good candidate to prepare new MCP structures.

In this study $\mathrm{ALD}$ was used to grow $\mathrm{TiO}_{2}$ films on the sub-micron diameter ion track structures in order to have low-resistivity and enhanced secondary electron production in the pores. The idea was that an ${ }^{16} \mathrm{O}$ beam releases secondary electrons upon collision with the pore walls. The secondary electron cloud can divide between crossing pores and further increase the number of electrons. With high secondary electron gain, this type of structures could act as low-cost electron multipliers in optical and various detector applications. The substrate for ALD in our case was a highly flexible porous ion track polyimide (Kapton) (Fig. $1)$.

\section{Experimental}

Self-supporting $50 \mu \mathrm{m}$ thick polyimide foils (Kapton from DuPont) were used as substrate material. The foils were irradiated using the JYFL K-130 cyclotron and Radiation Effects Facility (RADEF) irradiation chamber. The used ion was $600 \mathrm{MeV} \mathrm{Xe}^{25+}$, the fluence varied from $10^{7}$ to $10^{9}$ ions $/ \mathrm{cm}^{2}$, and individual irradiations lasted from seconds to thirty minutes. During the irradiations the beam homogeneity and flux were monitored. Irradiation angle was continuously varied between $\pm 15^{\circ}$ and the foil was also rotated in order to get crossing ion 
tracks in all directions, and thereby minimizing the probability of wide pores due to adjacent tracks.

The irradiated foils were etched in $\mathrm{NaOCl}$ solution [33]. The desired $\mathrm{pH}$ for the solution was obtained by adding boric acid $\left(\mathrm{H}_{3} \mathrm{BO}_{3}\right)$, and the $\mathrm{pH}$ was monitored before and after the etching. The $\mathrm{pH}$ was 10.5 in the beginning and 9.9 after the etching had been completed. The etching temperature was $\left(60 \pm 2{ }^{\circ} \mathrm{C}\right)$, and the etching time was 6 hours. The as-formed pores were imaged using a scanning electron microscope (Hitachi S-4800 FE-SEM), and the pore diameter was measured to be about $800 \mathrm{~nm}$.

In order to both enhance the secondary electron production from the pore surface and make the pore surface resistive, the porous foils were coated by atomic layer deposition with a $\mathrm{TiO}_{2}$ layer using TTIP (titanium tetraisopropoxide, $65{ }^{\circ} \mathrm{C}$ evaporation temperature) $+\mathrm{H}_{2} \mathrm{O}$ as precursors at $250{ }^{\circ} \mathrm{C}$. Each cycle had the following sequence: two times $0.5 \mathrm{~s}$ pulse and $1 \mathrm{~s}$ purge followed by 0.5 pulse and $15 \mathrm{~s}$ purge for TTIP, then the same for $\mathrm{H}_{2} \mathrm{O}$. Ca. $50 \mathrm{~nm} \mathrm{TiO}_{2}$ was deposited in 1500 cycles in a Picosun Sunale R-150 ALD reactor.

The film thickness $(47.7 \mathrm{~nm})$ was determined by X-ray reflectometry (Bruker D8 Advance ) using a $\mathrm{TiO}_{2}$ film, which was deposited onto a $100 \mathrm{~mm}(100) \mathrm{Si}$ wafer under the same conditions as used for the Kapton membranes. The growth rate per cycle corresponds well to the reported value $0.3 \AA$ /cycle [34].

XRD pattern of the reference $\mathrm{TiO}_{2}$ film on $\mathrm{Si}$ substrate was recorded by a PANalytical X'pert Pro MPD X-ray diffractometer using $\mathrm{Cu} \mathrm{K}_{\alpha}$ radiation and grazing incidence angle mode.

Consecutively, conducting $20 \mathrm{~nm}$ thick Au electrodes were electron beam evaporated on both sides of the ALD coated porous foils in an ultra high vacuum (UHV) environment.

The electron multiplication properties of the prepared foils were studied using a specially made setup (Fig. 2). The primary setup consisted of two coated $50 \mu \mathrm{m}$ thick polyimide foils which were separated by $2 \mathrm{~mm}$ conductive spacer ring. The voltage over the ALD-Kapton 
stack was evenly divided using two $1.2 \mathrm{M} \Omega$ resistors. The lower electrode had a fixed potential of $-1800 \mathrm{~V}$ and the potential of the upper electrode was varied between $-1625 \mathrm{~V}$ and $-2000 \mathrm{~V}$ in order to study the electron multiplication. The weak signals from Kapton electron multiplier were amplified by two conventional micro channel plates (MCP). The upper electrode of the MCP was set to a potential of $-1725 \mathrm{~V}$.

The operation of the Kapton/ $\mathrm{TiO}_{2}$ multipliers in ion detection was tested by backscattering a 4.8 $\mathrm{MeV}{ }^{16} \mathrm{O}^{2+}$ beam from the Pelletron accelerator from a thin $\mathrm{Au}$ target towards the foils. The energy of scattered ${ }^{16} \mathrm{O}$ ions was about $3.6 \mathrm{MeV}$, and the range in Kapton coated by 50 $\mathrm{nm} \mathrm{TiO}_{2}$ is about $4.1 \mu \mathrm{m}$ as calculated using SRIM. The measurement time for each point was $500 \mathrm{~s}$ and the number of events was normalized using the incident ion fluence information obtained from the beam chopper.

\section{Results and discussion}

The deposition of the ALD $\mathrm{TiO}_{2}$ film was successful on polyimide even at a growth temperature of $250{ }^{\circ} \mathrm{C}$ (Fig. 3). The $50 \mathrm{~mm}$ thick $\mathrm{Kapton} / \mathrm{TiO}_{2}$ porous membrane had ca. 800 $\mathrm{nm}$ diameter channels penetrating through the whole structure $(\mathrm{A} / \mathrm{R}=62.5)$. The small cracks visible on the $\mathrm{TiO}_{2}$ film on surface of the membrane are most likely due to polymer shrinkage during the cooling down after the ALD growth. The thermal expansion coefficient of polyimide is more than ten times higher than the one for $\mathrm{TiO}_{2}$. The good quality of coated foils proves the compatibility of ion track technology using polyimide foils with the ALD method even at fairly high deposition temperatures.

To check the conformality of the as-deposited $\mathrm{TiO}_{2}$ film, the coated membrane was annealed in air using $1{ }^{\circ} \mathrm{C} / \mathrm{min}$ heating rate up to $600{ }^{\circ} \mathrm{C}$ and then keeping the sample at $600{ }^{\circ} \mathrm{C}$ for an hour. As a result of the polyimide membrane combustion a porous inorganic membrane was 
obtained consisting of aligned $\mathrm{TiO}_{2}$ nanotubes (Fig. 4a). The wall thickness of the $\mathrm{TiO}_{2}$ nanotubes was around $50 \mathrm{~nm}$ as expected, and it was confirmed that the $\mathrm{TiO}_{2}$ film covered uniformly the pores all along their length (Fig. 4b). The figure shows that the complete removal of the polymer material joins the nanotubes together. During the annealing of the polymer, the originally cylindrical $\mathrm{TiO}_{2}$ film in the polymer channels became somewhat distorted, and the planar $\mathrm{TiO}_{2}$ layers on the top and back side of the membrane were not maintained. Most probably the applied heat and the considerable gas release during the decomposition and combustion of the polymer were responsible for this. In addition, the film thickness of the $\mathrm{TiO}_{2}$ film was not enough to provide suitable robustness to it as a selfstanding structure, which could have withstood the annealing of the polymer.

The structure of the as-deposited reference $\mathrm{TiO}_{2}$ film was measured by XRD. According to the XRD pattern (not shown here), $\mathrm{TiO}_{2}$ was present in the anatase form (ICDD 21-1272).

In Fig. 5 the number of pulses recorded from the commercial MCP anode is plotted as a function of the voltage over the ALD-Kapton two foil stack. The two first modes of operation of the device are easily understandable. If the voltage difference over the ALD-Kapton stack is negative, there is no voltage dependence as the possible electrons are accelerated away from the MCP and the count rate of about 12 counts per second is comparable to the background count rate of the MCP, with or without any backscattered oxygen ions. Once the voltage difference over the ALD-Kapton stack turns positive, there is a clear rising trend until the voltage difference of $75 \mathrm{~V}$, which corresponds to electric field of $75 \mathrm{kV} / \mathrm{m}$. Above this the count rate starts to fluctuate and saturate. The obvious explanation for the saturation could be that the maximum count rate for the active area of the ALD-MCP is already reached and higher voltage over the ALD-MCP stack will only increase the pulse height but not the number of pulses. A detailed pulse height analysis study will be performed in the future. 
The electron multiplication is not only dependent on the secondary electron production capability of the pore surface material but also on the electron energy. The flight path is longer and therefore also the energy of the electrons is higher for greater pore diameter and it could be that the $800 \mathrm{~nm}$ pore diameter these foils had is quite close to the diameter below which electrons do not get enough energy before colliding with the wall to multiply the yield. On the other hand, smaller pore diameter gives better spatial and temporal resolution. One special signal enhancing new property these ion track foils have is due to the crossing of the pores inside the polymer. The electrons can find their way to another pore and generate a strong daughter signal there as well.

\section{Conclusions}

In this study we have demonstrated the ability to combine ion track technology and ALD in fabrication of films with electron multiplication properties. $50 \mathrm{~nm} \mathrm{TiO}_{2}$ films were deposited onto $50 \mu \mathrm{m}$ Kapton foils, which had $800 \mathrm{~nm}$ crossing pores prepared previously by ion track method and chemical etching. The results show that electron multiplication can be achieved using the ALD-coated flexible ion track foils, although multiplication is not still strong enough for direct detection, and thus an extra amplification stage is needed, and further studies are required in finding the optimal pore diameter and ALD film thickness.

One additional possibility for applications opens when the supporting organic polymer is etched away like is shown in Fig. 3a, where an array of $800 \mathrm{~nm}$ wide $\mathrm{TiO}_{2}$ nanotubes with 50 $\mathrm{nm}$ wall thickness film is prepared after annealing at $600{ }^{\circ} \mathrm{C}$ in air. Due to the crossing tracks, the structure is still rigid and could be used as a highly porous substrate in, for instance, cell growth studies or catalysis. 


\section{Acknowledgements}

This work was supported under the auspices of Finnish Centre of Excellence Programme (Project No. 213503, 251353 Nuclear and Accelerator Based Physics). I.M.S. thanks for a Marie Curie Intra-European Fellowship (PIEF-GA-2009-235655), an OTKA-PD-109129 grant and a János Bolyai Research Fellowship of the Hungarian Academy of Sciences.

\section{References}

[1] E.C. Hammel, O.L.R. Ighodaro, O.I. Okoli, Ceram. Int. 40 (2014) 1535.

[2] C. RoyChaudhuri, Sens. Actuat. B 210 (2015) 310.

[3] R.V. Godbole, P. Rao, P.S. Alegaonkar, S. Bhagwat, Mater. Chem. Phys. 161 (2015) 135.

[4] H.J. Jeong, J. W. Kim, D.Y. Jang, J.H. Shim, J. Power Sources 291 (2015) 239.

[5] Kocakusakoglu, M. Daglar, M. Konyar, H.C. Yatmaz, K. Öztürk, J. Eur. Ceram. Soc. 35 (2015) 2845.

[6] O. Czakkel, E. Geissler, I.M. Szilágyi, K. László, Nanomat. Environ. 1 (2013) 23.

[7] Lim, D.Y. Lee, S.A. Patil, N.K. Shrestha, S.H. Kang, Y.C. Nah, W. Lee, S.H. Han, Mater. Chem. Phys. 148 (2014) 562.

[8] S. Gadipelli, Z.X. Guo, Prog. Mater. Sci. 69 (2015) 1.

[9] O. Czakkel, E. Geissler, I.M. Szilágyi, E Székely, K. László, J. Coll. Interface Sci. 337 (2009) 513.

[10] X. Du, S.Z. Qiao, Small, 11 (2015), 392.

[11] T. Gys, Nucl. Instr. Meth. A 787 (2015) 254.

[12] C. Trautmann, S. Bouffard, R. Spohr, Nucl. Instr. Meth. B 116 (1996) 429. 
[13] J. F. Ziegler, J. Biersack, U. Littmark, The Stopping and Range of Ions in Matter, Pergamon Press (1985)

[14] C. Trautmann, W. Brachle, R. Spohr, J. Vetter, N. Angert, Nucl. Instr. Meth. B 111 (1996) 70 .

[15] B.J. O’Neill, D.H.K. Jackson, J. Lee, C. Canlas, P.C. Stair, C.L. Marshall, J.W. Elam, T.F. Kuech, J.A. Dumesic, G.W. Huber, ACS Catal. 5 (2015) 1804.

[16] I.M. Szilágyi, E. Santala, M. Heikkilä, V. Pore, M. Kemell, G. Teucher, T. Firkala, E. Färm, T. Nikitin, L. Khriachtchev, M. Räsänen, M. Ritala, M. Leskelä, Chem. Vapor Dep. 19 (2013) 149.

[17] V. Miikkulainen, M. Leskelä, M. Ritala, R.L. Puurunen, J. Appl. Phys. 113 (2013) 021301.

[18] S. M. George, Chem. Rev. (110) 2009111.

[19] H. Kim, H.B.R. Lee, W.J. Maeng, Thin Solid Films 517 (2009) 2563.

[20] I.M. Szilágyi, D. Nagy, J. Phys. Conf. Ser. 559 (2014) 012010.

[21] C. Detavernier, J. Dendooven, S.P. Sree, K.F. Ludwig, J.A. Martens, Chem. Soc. Rev. $40(2011) 5242$.

[22] I.M. Szilágyi, G.Teucher, E. Härkönen, E. Färm, T. Hatanpää, T. Nikitin, L. Khriachtchev, M. Räsänen, M. Ritala, M. Leskelä, Nanotechnology 24 (2013) 245701.

[23] S.G. Kang, T. Kobayashi, Mater. Sci. Forum 449-452 (2004) 1165.

[24] J. Wang, K. Byrum, M. Demarteau, J. Elam, A. Mane, E. May, R. Wagner, D. Walters, L. Xia, J. Xie, H. Zhao, Nucl. Instr. Meth. A 804 (2015) 84.

[25] D.R. Beaulieu, D. Gorelikov, P. de Rouffignac, K. Saadatmand, K. Stenton, N. Sullivan, A.S. Tremsin, Nucl. Instr. Meth. A 607 (2009) 81. 
[26] O.H.W. Siegmund, J.B. McPhate, A.S. Tremsin, S.R. Jelinsky, R. Hemphill, H.J. Frisch, J. Elam, A. Mane, Nucl. Instr. Meth. A 695 (2012) 168.

[27] J. Xie, K. Byrum, M. Demarteau, E. May, R. Wagner, D. Walters, J. Wang, L. Xia, H. Zhao, Nucl. Instr. Meth. A 824 (2016) 159.

[28] Franco, Y. Riesen, N. Wyrsch, S. Dunand, F. Powolny, P. Jarron, C. Ballif, Nucl. Instr. Meth. A 695 (2012) 74.

[29] G. Drobychev, A. Barysevich, K. Delendik, A. Karneyeu, P. Nédélec, D. Sillou, O. Voitik, Nucl. Instr. Meth. A 567 (2006) 290.

[30] D.R. Beaulieu, D. Gorelikov, H. Klotzsch, P. de Rouffignac, K. Saadatmand, K. Stenton, N. Sullivan, A.S. Tremsin, Nucl. Instr. Meth. A 633 (2011) S59,

[31] D. Beaulieu, D. Gorelikov, H. Klotzsch, J. Legere, J. Ryan, P. de Rouffignac, K. Saadatmand, K. Stenton, N. Sullivan, A. Tremsin, Nucl. Instr. Meth. A 659 (2011) 394.

[32] S.J. Jokela , I.V. Veryovkin, A.V. Zinovev, J.W. Elam, A.U. Mane, Q. Peng, Z. Insepov, Phys. Proc. 37 (2012) 740.

[33] Z. Tian-Cheng, R. Brandt, P. Vater, J. Vetter, Nucl. Tracks Radiat. Measur. 15 (1988) 771.

[34] M. Ritala, M. Leskelä, L. Niinistö, P. Haussalo, Chem. Mater. 5 (1993) 1174. 


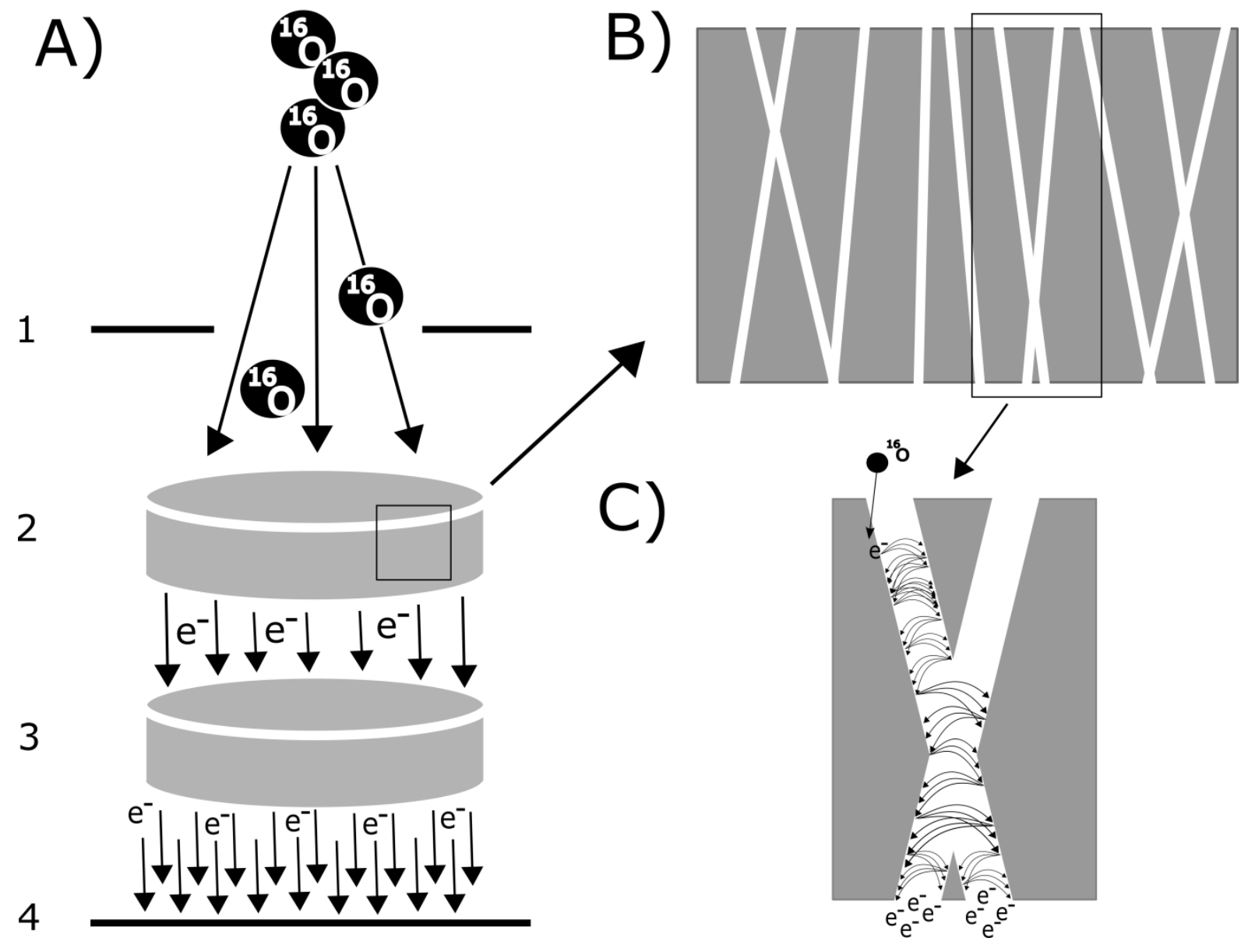

Figure. 1. A) Schematic diagram of the electron multiplier detector configuration. 1) 3,6 MeV $16 \mathrm{O}$ beam and aluminum collimator 2) porous polyimide foil 3) standard MCP used for post amplification of electron signal and 4) charge collecting plate. B) Polyimide foil thickness was $50 \mu \mathrm{m}$ and pore diameter $800 \mathrm{~nm}$. During the irradiation the foil was tilted between 0 and 15 degrees. C) The ion beam releases secondary electrons upon collision with the pore walls. The secondary electron cloud can divide between crossing pores and further increase the number of electrons. 


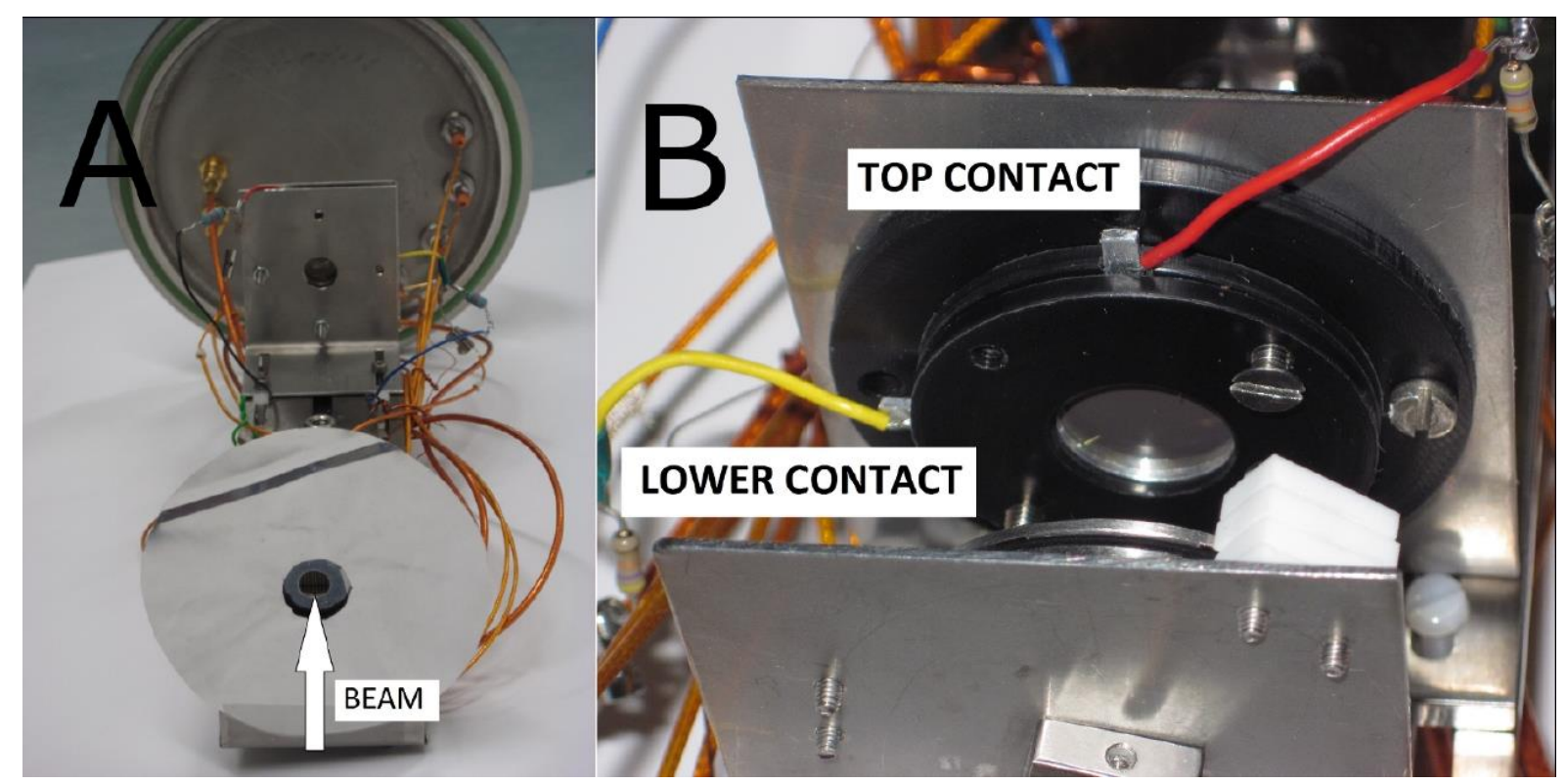

Figure 2. A) A photograph of the used setup showing the collimated entrance to the Kapton/ $\mathrm{TiO}_{2}$ MCP-ALD two foil stack where the scattered 3.6 MeV oxygen beam hits. In B) the same setup is shown from the opposite direction showing the stack and its top and lower contacts as well as the commercial MCP stack which was used to amplify the signal behind the metal plate. 


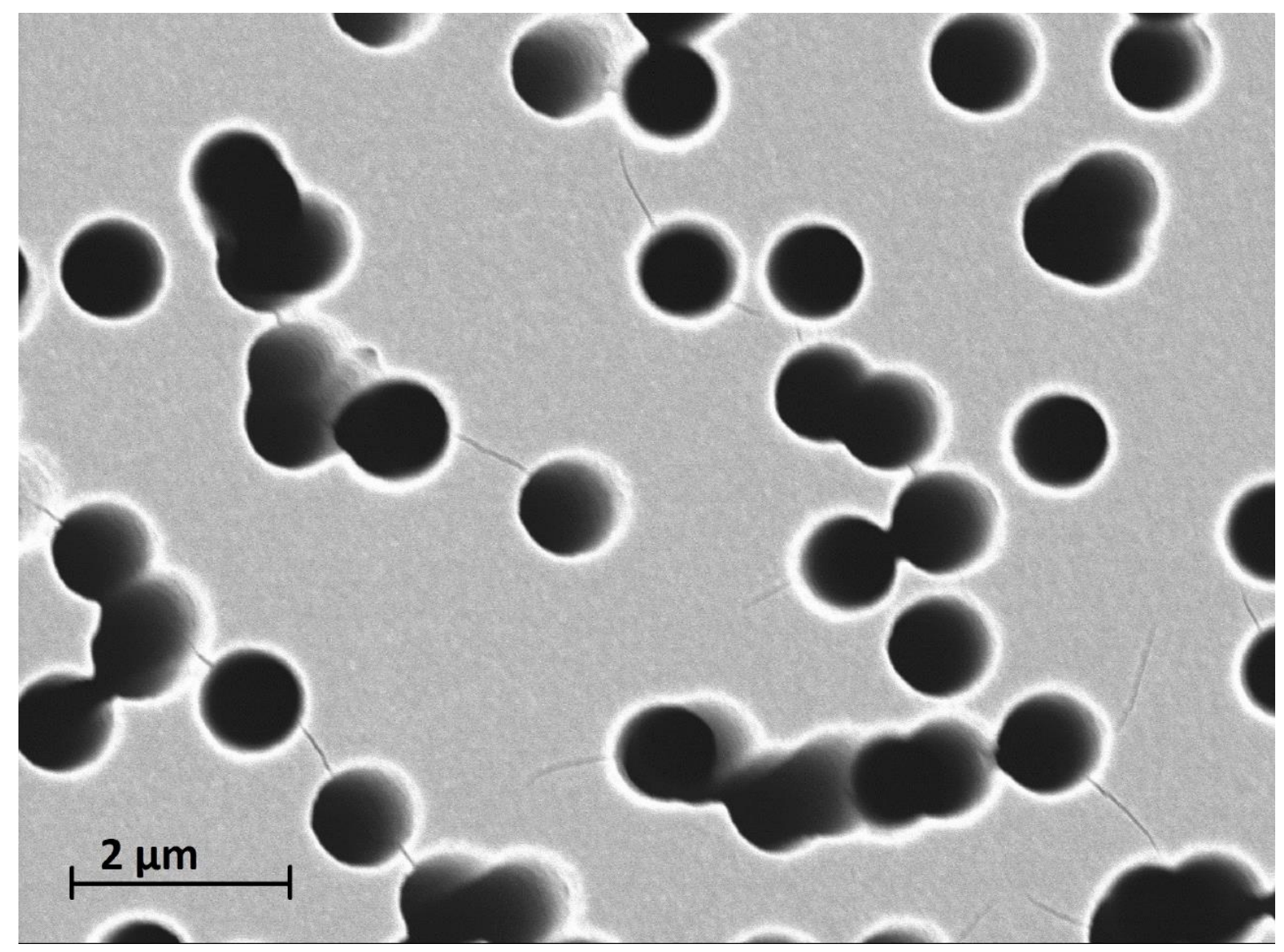

Figure 3. SEM image of the $\mathrm{TiO}_{2}$ coated porous Kapton membrane. A $50 \mu \mathrm{m}$ polyimide foil was irradiated with $600 \mathrm{MeV}$ Xe ions and etched for 6 hours in sodium hypocloride and boric acid solutions having $\mathrm{pH}$ 10.5. After etching a $50 \mathrm{~nm}$ ALD-TiO ${ }_{2}$ film was deposited on both sides but also on the pore inner surfaces. The final pore diameter was about $800 \mathrm{~nm}$. The small cracks on the $\mathrm{TiO}_{2}$ film are most likely due to polymer shrinkage during the cooling down after the ALD growth. 


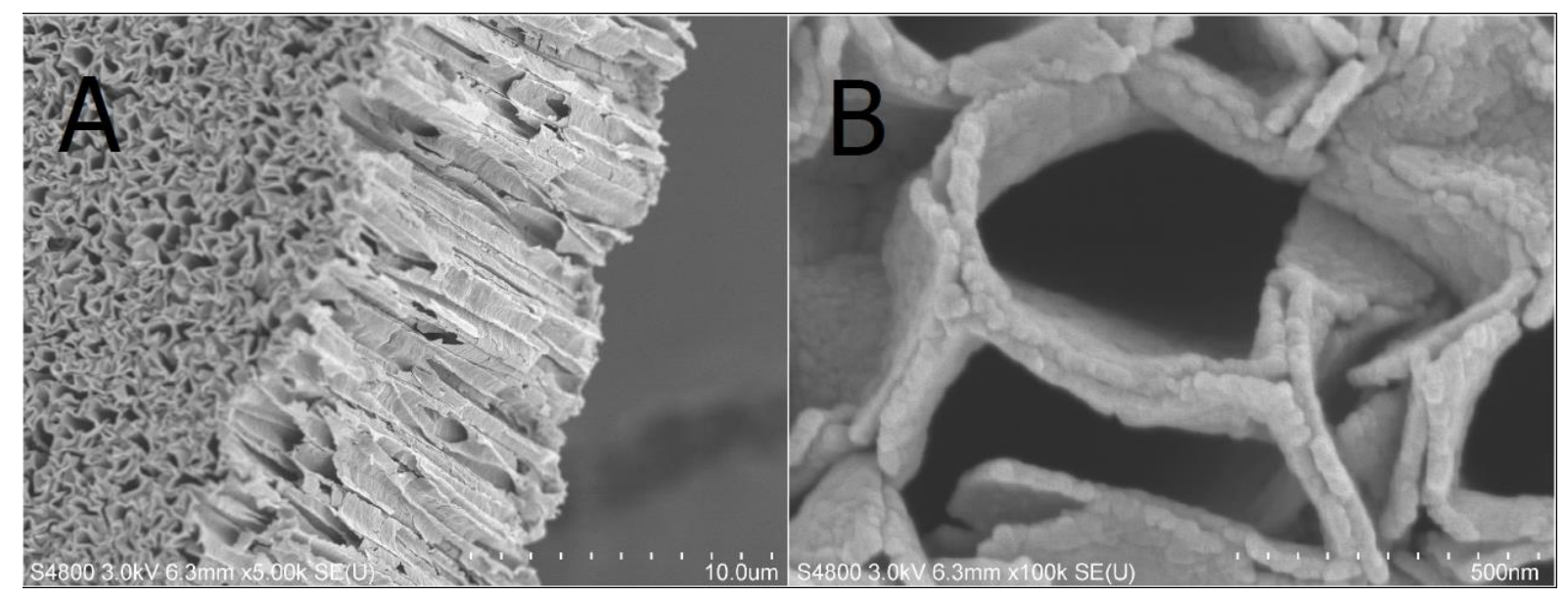

Figure 4. Self-supporting porous $\mathrm{ALD} \mathrm{TiO}_{2}$ membrane after removal of the polyimide substrate by annealing in air at $600{ }^{\circ} \mathrm{C}$. 


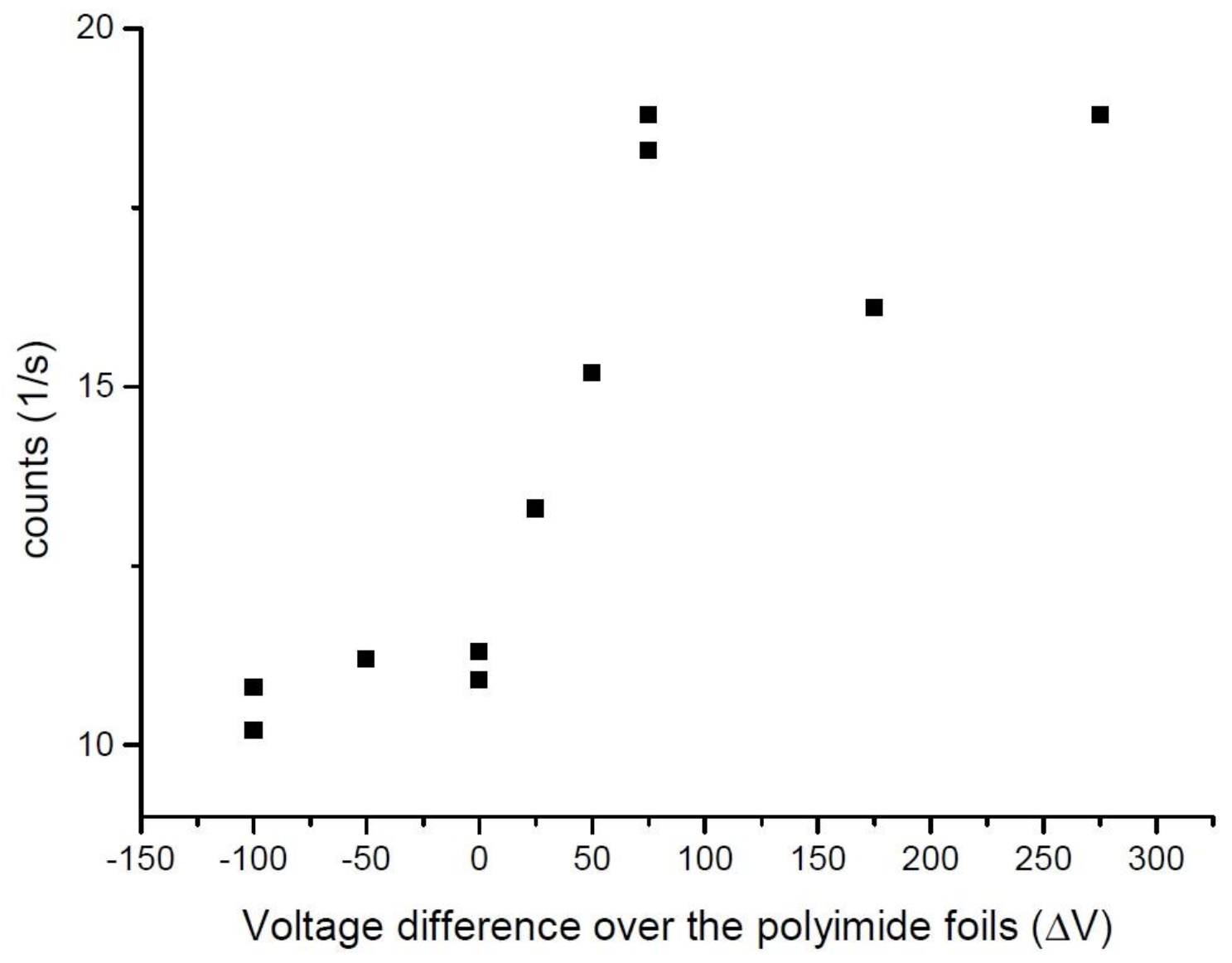

Figure 5. The number of counts per second as a function of the voltage difference over the two foil stack of Kapton/ $\mathrm{TiO}_{2}$ MCP-ALD membranes. 